\title{
Study of variability of ITS1 and ITS2 spacers of rDNA of freshwater sponges (Porifera, Spongillida)
}

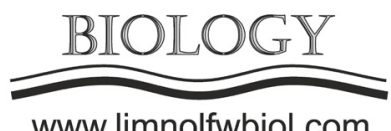

www.limnolfwbiol.com

\author{
Itskovich V.B. ${ }^{1 *}$, Sokolova A.M. ${ }^{2}$, Kaluzhnaya O. ${ }^{1}$, Yakhnenko A.S. ${ }^{1,3}$, Selvin J. ${ }^{4}$ \\ ${ }^{1}$ Limnological Institute, Siberian Branch of the Russian Academy of Sciences, Ulan-Batorskaya Str., 3, Irkutsk, 664033, Russia \\ ${ }^{2}$ N. K. Koltzov Institute of Developmental Biology, Russian Academy of Science, Vavilova str., 26, Moscow, 119334, Russia \\ ${ }^{3}$ Joint Institute for Nuclear Research, 6 Joliot-Curie St, Dubna, Moscow Region, 141980, Russia \\ ${ }^{4}$ Department of Microbiology, School of Life Sciences, Pondicherry University, Puducherry, 605014, India
}

\begin{abstract}
Molecular methods are especially important in the study of the taxonomy of sponges of ancient lakes, since when living at great depths, sponges lose their ability to form gemmules, and the structure of gemmules is an important taxonomic feature. However, the number of species and samples of freshwater sponges analyzed by molecular methods is insignificant today. In this work, we analyzed the variability of ITS1 and ITS2 of rDNA spacers of several species of freshwater sponges from geographically distant regions - Eastern Siberia, European Russia, Japan, and India. Our results confirmed the cosmopolitanism of the species Ephydatia fluviatilis and Spongilla lacustris and the adequacy of using ITS rDNA spacers for analyzing the phylogeny of freshwater sponges.
\end{abstract}

Keywords: Porifera, molecular phylogeny, ITS1 and ITS2, evolution, biodiversity

\section{Introduction}

Sponges (Porifera) are the most primitive multicellular animals and important component of marine and freshwater ecosystems (Van Soest et al., 2012; Webster et al., 2013). Freshwater sponge systematics and phylogeny are complicated because of the limited number of morphological features employed for taxonomy. Many species of freshwater sponges have the ability to produce gemmules, which contain totipotent cells and are resistant to extreme fluctuations of environmental conditions. The structure of gemmules are crucial for species identification of Spongillida. Often it is difficult to identify freshwater sponge species when collected samples do not contain gemmules.

Molecular analyses based mostly on the internal transcribed spacer (ITS) region and COXI sequences have provided us with a better understanding of freshwater sponge phylogeny (Itskovich et al., 2017; Schuster et al., 2018; Erpenbeck et al., 2019). This finding also indicates that the taxonomy of freshwater sponges needs urgent revision. The ITS region is one of the most variable parts of the genome and is most suitable for analyses of Spongillida phylogeny (Addis and Peterson, 2005; Itskovich et al., 2008; Erpenbeck et al., 2019). However, a small number of freshwater sponge samples have been analyzed to date. The aim of this work was to study interspecific and intraspecific variability of ITS of rDNA in the freshwater sponges of the family Spongillidae from different geographical locations.

\section{Materials and methods}

Total of 12 sponge specimens were collected in lakes of Eastern Siberia, the European part of Russia, Japan and India. DNA extraction, PCR amplification and sequencing of ITS1, 5.8S rDNA and ITS2 sequences were performed as previously described (Itskovich et al., 2017). Phylogenetic trees were constructed using the maximum likelihood (ML) method and Bayesian inference (BI), as implemented in MEGA 5 (Tamura et al., 2011) and MrBayes 3.1.2 (Ronquist and Huelsenbeck, 2003). For the ML analysis, the K2P $+\mathrm{G}$ model was the best fitting model. The robustness of the ML trees was estimated by bootstrap percentages (Felsenstein, 1985) using 500 replicates with heuristic search and stepwise addition starting trees. Bayesian analyses on nucleotide sequences were run with a parallel version of MrBayes 3.1.2 (Ronquist and Huelsenbeck, 2003). The robustness of the Bayesian trees was estimated by posterior probabilities.

\section{Results}

ITS sequences of 12 samples belonging to two species of Spongillidae were obtained, varying in length from 893 to 950 nucleotides. Seven sequences were 
identical, and five sequences have differences which included substitutions and indels in the ITS1 and ITS2. A BLAST analysis revealed that the obtained sequences are similar to Spongillida. On the phylogenetic trees all samples from Eastern Siberia, the European part of Russia, Japan and India identified by morphology as Ephydatia sp. formed a strongly supported monophyletic clade with samples of E. fluviatilis from GenBank. All analyzed S. lacustris samples also formed a robust clade, including our samples from Eastern Siberia, the European part of Russia and Japan (ML 99\%, BI 1.0). The level of intraspecies variability of ITS1 and ITS2 was $0-1.7 \%$ for $\mathrm{E}$. fluviatilis and $0-0.4 \%$ for S. lacustris. Interspecifc variability was significantly larger than the variability within species for most Spongillidae species including sequences available from GenBank.

Sponges have shown to be sensitive to changes in surrounding conditions (López-Legentil et al., 2008; Webster et al., 2013). Mass diseases and mortality events were noted for both marine and freshwater sponges, including sponges inhabiting Lake Baikal. Estimation of abundance and taxonomic composition of specific sponge populations at regular intervals should be a important part of the program of ecological monitoring. Our results support the adequacy of using of ITS spacers of rDNA for species identification of Spongillidae. Newly obtained sequences of E. fluviatilis and S. lacustris from different geographical locations support monophyly and cosmopolitanism of these species.

\section{Acknowledgments}

The work was supported by basic funding № 0345-2019-0002, by RFBR and DST according to the research project № 19-54-45034 and RFBR № 20-0400868. The work of AMS was conducted under the IDB RAS GBRP in 2020 № 0088-2019-0005.

\section{References}

Addis J.S., Peterson K.J. 2005. Phylogenetic relationships of freshwater sponges (Porifera, Spongillina) inferred from analyses of 18S rDNA, COI mtDNA, and ITS2 rDNA sequences. Zoologica Scripta 34: 549-557. DOI: 10.1111/j.1463-6409.2005.00211.x

Erpenbeck D., Steiner M., Schuster A. et al. 2019. Minimalist barcodes for sponges: a case study classifying African freshwater Spongillida. Genome 62: 1-10. DOI: 10.1139/gen-2018-0098

Felsenstein J. 1985. Confdence limits on phylogenies: an approach using the bootstrap. Evolution 39: 783-791. DOI: 10.1111/j.1558-5646.1985.tb00420.x

Itskovich V., Kaluzhnaya O., Veynberg Y. et al. 2017. Endemic Lake Baikal sponges from deep water. 2: Taxonomy and bathymetric distribution. Zootaxa 4236: 335-342. DOI: 10.11646/zootaxa.4236.2.8

Itskovich V., Gontcharov A., Masuda Y. et al. 2008. Ribosomal ITS sequences allow resolution of freshwater sponge phylogeny with alignments guided by secondary structure prediction. Journal of Molecular Evolution 67: 608-620. DOI: $10.1007 / \mathrm{s} 00239-008-9158-5$

López-Legentil S., Song B., McMurray S.E. et al. 2008. Bleaching and stress in coral reef ecosystems: Hsp70 expression by the giant barrel sponge Xestospongia muta. Molecular Ecology 17: 1840-1850. DOI: 10.1111/j.1365-294X.2008.03667.x

Ronquist F., Huelsenbeck J.P. 2003. MrBayes 3: Bayesian phylogenetic inference under mixed models. Bioinformatics 19: 1572-1574. DOI: 10.1093/bioinformatics/btg180

Schuster A., Vargas S., Knapp I.S. et al. 2018. Divergence times in demosponges (Porifera): frst insights from new mitogenomes and the inclusion of fossils in a birth-death clock model. BMC Evolutionary Biology 18. DOI: 10.1186/ s12862-018-1230-1

Tamura K., Peterson D., Peterson N. et al. 2011. MEGA5: molecular evolutionary genetics analysis using maximum likelihood, evolutionary distance, and maximum parsimony methods. Molecular Biology and Evolution 28: 2731-2739. DOI: $10.1093 / \mathrm{molbev} / \mathrm{msr} 121$

Van Soest R.W.M., Boury-Esnault N., Vacelet J. et al. 2012. Global diversity of sponges (Porifera). PLoS One 7. DOI: 10.1371/journal.pone.0035105

Webster N., Pantile R., Botté E. et al. 2013. Complex life cycle in a warming planet: gene expression in thermally stressed sponges. Molecular Ecology 22: 1854-1868. DOI: $10.1111 / \mathrm{mec} .12213$ 